Original article

\title{
HAEMATOLOGICAL, BLOOD BIOCHEMICAL AND IMMUNO- LOGICAL RESPONSES TO GRADUAL ACCLIMATION TO LOW-SALINITY WATER IN WALTON'S MUDSKIPPER PERIOPH- THALMUS WALTONI KOUMANS, 1941 (PERCIFORMES: GOBIIDAE)
}

\section{S. SOLTANIAN \& M. S. FEREIDOUNI}

Aquatic Animal Health and Diseases Department, School of Veterinary Medicine, Shiraz University, Shiraz, Iran

\begin{abstract}
Summary
Soltanian, S. \& M. S. Fereidouni, 2019. Haematological, blood biochemical and immunological responses to gradual acclimation to low-salinity water in Walton's mudskipper Periophthalmus waltoni Koumans, 1941 (Perciformes: Gobiidae). Bulg. J. Vet. Med., 22, No 1, 13-25.

The present study investigates and reports the effects of gradual acclimation to low salinity water on some haematological, biochemical and immunological responses in Walton's mudskipper, $\mathrm{Pe}$ riophthalmus waltoni. For this purpose, mudskippers caught from Persian Gulf coastal area (Bandar Khamir, Hormozgan Province, Iran) were maintained in laboratory aquaria with half seawater (50\% $\mathrm{SW}, 17 \mathrm{ppt}$ ) and fed daily with frozen blood worms (Chironomus spp.) for one month prior to the start of experiments. After acclimation, groups of 18 individuals were either directly transferred to $50 \% \mathrm{SW}$ (control), or acclimated to low salinity water during two sub-periods. In the first sub-period, fish were exposed to low salinity water namely to a gradual water salinity decrease of 1 ppt per day (during 17 days) until the final salinity of $0.4 \mathrm{ppt}$ was reached. Afterwards, fish continued to maintain in this point of salinity ( $0.4 \mathrm{ppt}$ ), for further 15 days until day 32 (second sub-period). Fish were sampled on day 0, 17 and 32. Statistical analysis showed a significant influence of reduced salinity on erythrocytes, haemoglobin, haematocrit, leukocytes, lymphocytes, neutrophils, monocytes and on all biochemical and immunological parameters tested on day 17. However, these indices returned to the control level on day 32. Based on results, the extremely euryhaline P. waltoni can be acclimated to freshwater medium without showing any health disturbance if a gradual decrease in salinity is carried out for a long period of time.
\end{abstract}

Key words: acclimation, euryhaline, oxudercine gobies, salinity, stress

\section{INTRODUCTION}

Environmental salinity is a very important factor for aquatic organisms and any change in salinity seriously affects the osmotic pressure and metabolism (Musta- fayev \& Mekhtiev, 2008; Fazio et al., 2013), causes changes to the activity, structure, and physiological function of fish digestive enzymes; and affects fish 
development, habits and survival (Wang \& Zhu, 2002; Ruscoe et al., 2004). In fish, studies on the effect of salinity have mainly looked at changes in osmoregulatory organs and their hormonal control, plasma parameters, energy metabolism, growth etc. (McCormick, 2001). However, little is known about the changes in the fish immune system after salinity disturbance despite the fact that salinity is one of the most important environmental factors in the aquatic medium. On the other hand, the haematological profile is a good indicator of physiological dysfunctions since there is a close association of circulatory system with the external environment (Elahee \& Bhagwant, 2007). It provides information not only about the health status of fish and the physical and chemical parameters of water in which they live, but also allows assessing the relationship between these factors and the susceptibility of organisms to changes in environmental conditions (Elahee \& Bhagwant, 2007; Maceda-Veiga et al., 2010; Ayoola et al., 2011).

There are some fish species that can tolerate various salinities and a few that can survive extended exposure in water with different salinities (Nordlie \& Haney, 1998). According to Francis et al. (2007), salinity is one of the most fluctuating water quality parameters in brackish water environment. Growth of euryhaline species is often affected by salinity because the energy used for osmoregulation is not available for growth (Wootton, 1990). Consequently, many of these species have an optimum salinity level at which the growth rate is highest and the cost of osmoregulation lowest, which may affect fish distribution in the wild (Blaber, 1997).

Mudskippers (Teleostei: Gobiidae: Oxudercinae: Periophthalmini) are gobies that are fully terrestrial for some portion of the daily cycle (Murdy, 1989). They are subject of biological and ecotoxicological studies, to determine their potential use as a bio-indicator in environmental assessments of coastal waters, tropical or subtropical soft bottom intertidal systems (Aligaen \& Mangao, 2011). They could be also a reliable aquarium or ornamental fish (Mleczko, 2003).

The mudskippers are euryhaline and can withstand rapid and drastic changes in salinity (Aligaen \& Mangao, 2011). The Walton's mudskipper (Periophthalmus waltoni, Koumans, 1941), is one of the three species of oxudercine gobies (Gobiidae) (Agorreta et al., 2013), living in the Persian Gulf and Gulf of Oman (Murdy, 1989; Ghanbarifardi et al., 2014a,b,c; 2016). Iranian mudskippers are differentially distributed from more aquatic to more terrestrial habitats, respectively, from Scartelaos tenuis to Boleophthalmus dussumieri to P. waltoni (Clayton, 1985). P. waltoni has been recorded in a wide range of intertidal habitats, including tidal mudflats and mangrove forests (Clayton, 1985; Ghanbarifardi \& Malek, 2007). Such environments, are particularly harsh during low tide, including rapid and wide fluctuations of temperature (Tytler \& Vaughan, 1983) and salinity (Sasekumar, 1994). Therefore, the natural habitat of $P$. waltoni lies usually in a dynamic state of fluctuating salinities. Movement between fresh water and brackish or seawater causes physiological changes, including blood composition fluctuations.

Limited information exists with respect to the effects of salinity on physiology of $P$. waltoni. Hence, the present work aimed to examine the possible variations of blood profile and immune responses in $P$. waltoni as a result of gradual acclimation to reduced salinity. 


\section{MATERIALS AND METHODS}

\section{Collection and maintenance of mudskippers}

Live specimens of Walton's mudskipper, $(\mathrm{n}=36 ; 10.6 \pm 2.8 \mathrm{~cm}$ total length; $7.2 \pm 1.9$ $\mathrm{g}$ weight) were collected by hand from the mudflats of the coastal area of the Persian Gulf in Bandar Khamir (Hormuzgan Province, Iran; $\left.26^{\circ} 56^{\prime} 40^{\prime \prime} \mathrm{N}, 5^{\circ} 35^{\prime} 55^{\prime \prime} \mathrm{E}\right)$. Fish were morphologically identified to species level by means of the available morphological keys (Murdy, 1989). The animals were brought to the laboratory in plastic troughs containing only sea water to $3 \mathrm{~cm}$ level. They were maintained under laboratory conditions in $50 \%$ salinity water (SW) or $17 \mathrm{ppt}$ in small aquaria $(70 \times 35 \times 35 \mathrm{~cm}$, water depth approximately $3 \mathrm{~cm}$ ) at $25{ }^{\circ} \mathrm{C}$, providing appropriate terrestrial areas to the fish. Different salinities were provided by dilution of coastal Persian Gulf saline water (approximately $35 \mathrm{ppt}$ ) with dechlorinated municipal freshwater. Salinity was determined by using hand-held refractometer (Model HRN-2N Atago Product Japan). Fish were fed frozen blood worms ( $\mathrm{Chi}$ ronomus spp.) ad libitum once daily in the morning, and the water was changed every other day. They were allowed to adapt to such environment for a month before experiments were performed.

\section{Gradual acclimation of mudskippers to freshwater}

After the holding period, the fish were randomly divided into two equal treatments. Each treatment was replicated 3 times with 6 fish in each aquarium. The first group of fish was directly transferred to $50 \% \mathrm{SW}$ and served as control. The second group of fish was acclimated to low salinity water during two sub-periods. In the first sub-period, fish were exposed to low salinity water - gradual water salinity decrease of 1 ppt per day (over a period of 17 days) until the final salinity of $0.4 \mathrm{ppt}$ (the salinity of freshwater) was reached. Fish were maintained at this salinity $(0.4 \mathrm{ppt})$, for another 15 days until day 32 (second sub-period). Salinity was checked every day and adjusted when necessary. In both treatments, fish were free to be in or out of water using appropriate terrestrial areas inside aquaria. They were fed frozen blood worms (Chironomus spp.) once daily in the morning, and the water was changed every other day. During the trial, all fish were maintained under natural photoperiod (sunrise at 05:55 h, sunset at 20:00 h) and temperature, salinity, dissolved oxygen levels and ammonia concentration were measured based on the methods described by APHA (1985).

\section{Blood collection}

Six fish were sampled at random from each experimental and respective control group at days 0,17 and 32 . On the sampling points, fish were randomly collected in the tanks with nets and anaesthetised in MS-222 (Sigma-Aldrich) (150 mg/L). Blood samples were collected from caudal vein using a $2 \mathrm{~mL}$ syringe and a 24 gauge needle. Haematological parameters were assessed within one hour of blood collection. One part of each sample was transferred into preheparinised plastic Eppendorf tubes while the other part - into blood collecting tubes or Eppendorf tubes without anticoagulant and was allowed to clot for $2 \mathrm{~h}$ at room temperature in a slanting position. The clot was then cut with a glass rod and care was taken not to haemolyse it. The tubes were kept at $4{ }^{\circ} \mathrm{C}$ overnight and then centrifuged at $2500 \times g$ for $15 \mathrm{~min}$ and the supernatant serum was collected. The serum was stored at $-80{ }^{\circ} \mathrm{C}$ in screw cap glass vials until use. 


\section{Haematological and blood biochemical parameters}

Blood samples were immediately analysed for estimation of numbers of erythrocytes (RBC) and leukocytes (WBC), haemoglobin $(\mathrm{Hb})$ and haematocrit (Hct). RBC and WBC counts were determined as described in Schaperclaus et al. (1991). Haemoglobin content $(\mathrm{Hb})$ was assayed using the cyanmethaemoglobin method with Drabkin's solution (Goldenfarb, 1971). Haematocrit was determined by the microhematocrit method (Fox, 1997). The mean corpuscular volume (MCV), the mean corpuscular haemoglobin $(\mathrm{MCH})$ and the mean corpuscular haemoglobin concentration (MCHC) were calculated using the formulas (Jain, 1993.:

For differential WBC counts, whole blood was smeared on glass microscope slides, dried in air, and stained with MayGrunwald/Giemsa. Leukograms were assessed for each fish under an oil immersion lens. One hundred white blood cells from each smear were assessed and the percentages of different types of leukocytes were calculated (Schaperclaus et al., 1991). The quantitative determination of glucose was carried out using commercially available diagnostic kit (Pars Azmun, Iran, 1500 0178) (Hosseini et al., 2011), at $546 \mathrm{~nm}$ and $37^{\circ} \mathrm{C}$ according to the glucose oxidase method suggested by Trinder (1969). Lactate was measured with an enzymatic method by a lactate kit (Pars Azmoon, Tehran, Iran). Total serum protein was measured by the Biuret method (Kwapinski, 1965).

\section{Immunological parameters}

Phagocytic activity ex vivo. The phagocytic activity of whole blood cells was analysed using commercial baker's yeasts, Saccharomyces cerevisiae, as indicator according to Zhou et al. (2002). Dried live yeasts were incubated in $2 \%$ sucrose solution ( $\mathrm{pH} \mathrm{3-4)} \mathrm{for} 2 \mathrm{~h}$ at $30{ }^{\circ} \mathrm{C}$ and boiled for $30 \mathrm{~min}$. The yeast was then centrifuged and the pellet washed twice and re-suspended in $0.85 \%$ saline (at $2 \times 10^{8}$ cell $/ \mathrm{mL}$ ). A $20 \mu \mathrm{L}$ aliquot of suspension as well as $40 \mu \mathrm{L}$ heparinised whole blood was then added to a $0.1 \mathrm{~mL}$ Eppendorf tube and the mixture incubated at $30{ }^{\circ} \mathrm{C}$ for $30 \mathrm{~min}$ with gentle shaking. After this period, smears were prepared and the air-dried slides then stained with Wright-Geimsa stain. Phagocytic activity (PA) was determined by evaluating 100 phagocytes per slide using a light microscope. A minimum of 3 slides/fish was evaluated. The mean PA was calculated as $100 \times$ number of phagocytic cells with engulfed yeast cells/number of phagocytes counted.

Respiratory burst activity. Oxidative radical production by neutrophils during respiratory burst was measured by the NBT (nitroblue tetrazolium) assay as described by Anderson \& Siwicki (1995). Briefly, blood and $0.2 \%$ NBT were mixed in equal proportion $(1: 1)$, incubated for 30 min at $25{ }^{\circ} \mathrm{C}$, and then $50 \mu \mathrm{L}$ was taken out and dispensed in glass tubes. For solubilisation of reduced formazan product, $1 \mathrm{~mL}$ of dimethylformamide (Sigma, USA) was added and centrifuged at $2000 \times g$ for $5 \mathrm{~min}$. Finally, the supernatant was taken and the extent of NBT reduced was measured at an optical density of $540 \mathrm{~nm}$. Dimethylformamide was used as blank.

Lysozyme assay. Serum lysozyme activity was determined using the method described by Jian \& Wu (2003). Briefly, a suspension of an overnight grown Micrococcus lysodeikticus was prepared by dissolving $20 \mathrm{mg}$ of $M$. lysodeikticus into $100 \mathrm{~mL}$ of $0.067 \mathrm{~mol} / \mathrm{L}$ sodium phosphate buffer, $\mathrm{pH} \quad 6.4$ and then, $100 \mu \mathrm{L}$ of fish 

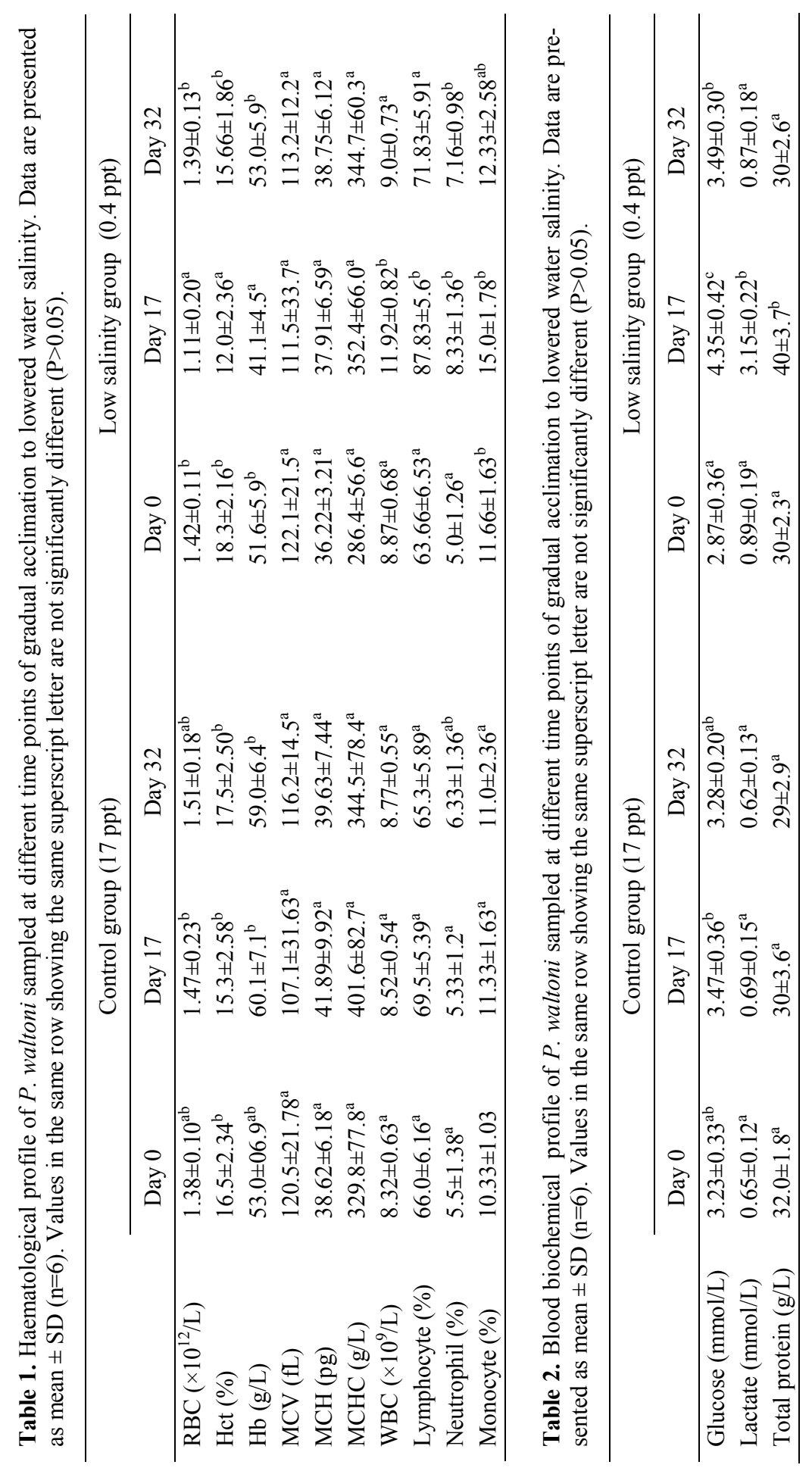

BJVM, 22, No 1 
Haematological, blood biochemical and immunological responses to gradual acclimation to ....

serum was added to a $3-\mathrm{mL}$ suspension of M. lysodeikticus. The reaction was carried out at $25^{\circ} \mathrm{C}$ and an absorbance at $540 \mathrm{~nm}$ was measured after 0.5 and $4.5 \mathrm{~min}$. One unit of lysozyme activity was defined as the amount of lysozyme producing a decrease in absorbance of $0.001 / \mathrm{min}$.

\section{Statistical analysis}

Data are presented as mean \pm SD. Haematological, biochemical and immunological parameters were analysed by one way analysis of variance (ANOVA) and Tukey's multiple comparison test. All statistical analyses were tested at the 0.05 level of probability, using the software SPSS 16.0 for Windows.

\section{RESULTS}

No abnormal behaviour or mortality was seen in the medium during the entire period of acclimation to lowered salinity. All fish were considered healthy on the basis of an external examination for any signs of abnormalities. MCV, $\mathrm{MCH}$ and $\mathrm{MCHC}$ remained unchanged during the study, however, the number of erythrocytes, $\mathrm{Hb}$ and Hct levels were significantly diminished in fish sampled from lowered salinity treatment on day 17 but returned to the control level on day $32(\mathrm{P}<0.05)$ (Table 1$)$. In contrast, the opposite of the above discussed pattern was found for the number of WBC and the percentage of lymphocytes, neutrophils and monocytes as well as total protein and lactate levels which were significantly increased on day 17 and then declined to the control level on day $32(\mathrm{P}<0.05)$ (Tables 1 and 2$)$.

In addition, variation in levels of activities was pronounced for phagocytosis, lysozyme and respiratory burst activity, such that fish sampled from lowered salinity treatment on day 17 , had significantly

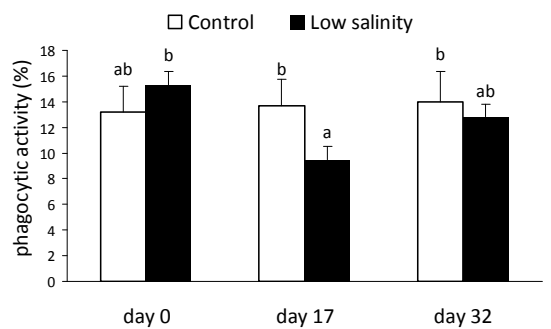

Fig. 1. Phagocytic activity of peripheral blood leukocytes of $P$. waltoni sampled at different time points of gradual acclimation to lowered water salinity (mean $\pm \mathrm{SD} ; \mathrm{n}=6$ ). Different letters over bars indicate a statistically significant difference $(\mathrm{P}<0.05)$.

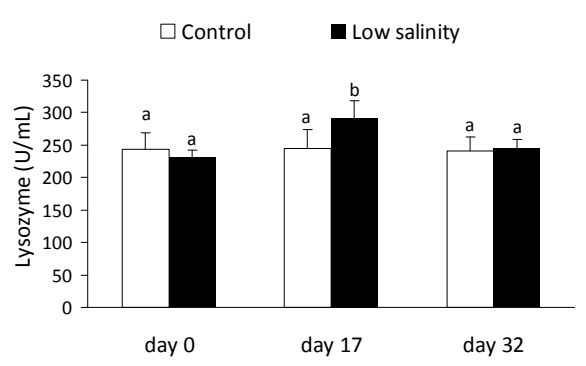

Fig. 2. Serum lysozyme activity of $P$. waltoni sampled at different time points of gradual acclimation to lowered water salinity (mean \pm SD; $n=6)$. Different letters over bars indicate a statistically significant difference $(\mathrm{P}<0.05)$.

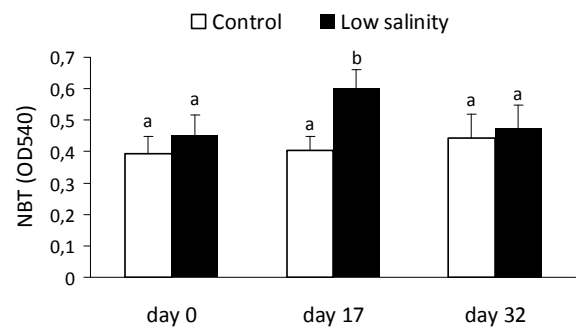

Fig. 3. NBT activity of peripheral blood leukocytes of $P$. waltoni sampled at different time points of gradual acclimation to lowered water salinity. Bars represent mean \pm SD $(n=6)$. Different letters over bars indicate a statistically significant difference $(\mathrm{P}<0.05)$. 
lower phagocytosis value but showed higher lysozyme and respiratory burst activity than respective control fish. However, these indices returned to the control level on day $32(\mathrm{P}<0.05)$ (Fig. 1, 2 and 3$)$.

\section{DISCUSSION}

Fish haematological parameters are closely correlated to the response to the environmental and biological factors such as age, weight, sex, food, bacteria, parasite and water quality parameters, including water temperature, salinity, oxygen availability and pH (Haider, 1973; Steinhagen et al., 1990; Fernandes \& Mazon, 2003). Our results for $P$. waltoni showed a significant influence of lowered salinity on most of the parameters studied on day 17 . However, in accordance with the previous studies (Gabriel et al., 2007; Akinrotimi et al., 2010; 2012), no changes occurred in $\mathrm{MCV}, \mathrm{MCH}$ and $\mathrm{MCHC}$ values between treatments on any sampling date. Nevertheless, significant reduction in the level of $\mathrm{RBC}$, Hct and $\mathrm{Hb}$ was observed on day 17 compared to the control group. These reductions may be attributed to salinity-induced osmoregulatory dysfunction which led to erythrocyte fragility (Girling et al., 2003). In fact, osmotically obliged water movement due to increased blood osmolality reduced blood haematocrit and haemoglobin concentrations at lower salinities. Furthermore, the observed haemodilution may be a consequence of impaired erythropoiesis (production of erythrocytes) caused by disrupted osmoregulation (Gabriel et al., 2007).

Hyperglycaemia is an expected result of stress or exhaustive exercise in fishes (Hrubec et al., 1997). It is known that the degree of hyperglycaemia may change depending on the type of stress and the sampling times (Rolland et al., 1997).
Lactate is produced by anaerobic metabolism in the muscle under stressful conditions of hypoxia or strenuous exercise and released to the plasma (Begg \& Pankhurst, 2004). In addition, lactate can provide energy for brain, gills and kidney (Mommsen, 1984). In our study, increase in the lactate levels on day 17 observed in fish exposed to lowered salinity, suggests that this metabolite is presumably used as an energy source by osmoregulatory organs. Similar results were obtained in common carp and Senegalese sole (Solea senegalensis) when fish were exposed to a sudden change of salinity (Salati et al., 2010; Herrera et al., 2012).

Total plasma protein concentration relative to a reference interval is used as a broad clinical indicator of health, stress, and well-being of aquatic organisms (Riche, 2007). In the current study, protein level increased in fish kept at low salinity level. In fact, our data are in agreement with the findings of Fazio et al. (2013), who addressed the possible importance of increased serum protein as a fuel for tissues during osmotic acclimation once carbohydrate stores have been mobilised. Amino acids seem to play an important role in allowing fish to adjust to the different environmental salinities, either as energy sources or as important osmolytes for cell volume regulation (Aragão et al., 2010). Elevated serum or plasma protein levels had previously been reported in starved red sea bream (Chryrosphrys major), black sea bream (Mylio macrocephalus) and red grouper (Epinephelus akaara) exposed to low salinity environments (Woo \& Murat, 1981; Woo \& Wu, 1982). Furthermore, in accordance with our study, serum protein concentrations were significantly elevated in silver sea bream (Spams sarba) as the ambient salinity diminished (Chun-yin, 2001). 
Understanding changes in innate immunity is relevant for evaluating changes in the general health of aquatic environment inhabitants (Skouras, 2002). Nevertheless, the effects of salinity are not well documented despite its importance in fish immunity and disease resistance. In fact, few studies revealed that salinity change can modulate the immune response in fish species (Jiang et al., 2008; Birrer et al., 2012; Schmitz et al., 2016).

Therefore, in the current study, the effects of salinity disturbance on mudskipper immune system were evaluated for the first time.

Some studies have investigated the changes in numbers and composition of circulating leukocytes following acute and chronic stress (Davis et al., 2008). Indeed, leukocytes are good physiological stress indicators in fish (Svobodová et al., 2001). The present study demonstrated significant increase in the total number of WBC as well as in lymphocytes, neutrophils and monocytes in fish exposed to lowered salinity on day 17. Conversely, no changes in leukocyte numbers in dolphin fish, Coryphaena hippurus (L.) was observed after a sudden drop in salinity occurred. However, comparable findings were observed in green back flounder Rhombosulea tapirina (Girling et al., 2003) and in Tilapia guineensis (Akinrotimi et al., 2010) exposed to fresh water. Furthermore, pipefish (Syngnathus typhle), kept under low salinity (6 ppt) revealed higher monocyte counts in the blood compared to the ambient salinity (18 ppt) and the high salinity (30 ppt) treatments (Birrer et al., 2012). However, the amount of monocytes correlated negatively with the amount of lymphocytes (Birrer et al., 2012) which is in contrast with the pattern observed in our findings. On the other hand, an increment in the number of monocytes and neutrophils was also noticed in stripped catfish (Pangasianodon hypophthalmus) exposed to chronic hyperosmotic environment (Schmitz et al., 2016). This increment might be due to a non-specific immune response to stress as a result of interaction of prolactin and cortisol hormone to restore ion balance in hyposmotic environment (McCormick, 2015). An increase in the count of WBC may also be caused by a release of cells accumulated in the spleen, to combat the stressor (Ajani et al., 2007).

Changes occurring in innate immune parameters can be useful indicators in assessing the condition of chronic stress induced by various stressors (Caruso et $a l$. , 2005). It was reported earlier that stress affects the lysozyme level or activity, phagocytic and/or respiratory burst activity of blood leukocytes (Thompson et al., 1993; Pulsford et al., 1994; Vazzana et al., 2002; Liebert \& Shreck, 2006). In the current study, significantly higher lysozyme and respiratory burst activity but lower phagocytic activity was observed in fish sampled from lowered salinity treatment on day 17. A comparable finding was observed in phagocytosis value in Nile tilapia, which significantly increased in response to decrease in salinity from 20 $\mathrm{g} / \mathrm{L}$ to $5 \mathrm{~g} / \mathrm{L}$ (Choi et al., 2013). In addition, exposure of tilapia (Oreochromis mossambicus) to hyperosmotic conditions significantly increased phagocytic ability as well as serum lysozyme and respiratory burst activities (Jiang et al., 2008). Increase in lysozyme activity and phagocytosis were also found in salmon during freshwater to sea water transfer (Marc et al., 1995). In fact, following stress in teleosts, both enhancement and suppression of plasma lysozyme activity have been reported, depending on the type, intensity and duration of the stressor (Fevolden et 
al., 2003). For example, higher lysozyme activities during both acute and chronic hyperosmotic stress have been described in euryhaline species (Marc et al., 1995; Yada et al., 2001; Jiang et al., 2008). Therefore, the level of serum lysozyme activity is recognised as a stress indicator of fish (Fevolden et al., 1999).

To conclude, acclimation of mudskipper to freshwater altered blood profiles and immune parameters according to the acclimation time. These results might be explained by the effects of osmoregulatory hormones and the involvement of different organs in the immune and osmoregulatory responses. Based on our results, the extremely euryhaline $P$. waltoni has been found to be very tolerant to low salinities and able to withstand gradual transfer from brackish water to salinities as low as $0.4 \mathrm{ppt}$ without showing any mortalities or even any abnormal behaviour during the acclimation period. Further, there are no indications that low salinities have detrimental effects on blood profile and/or immunity-related parameters after a long-term acclimation. Thus, the study points at an economic advantage and easier rearing of $P$. waltoni as an ornamental fish in freshwater rather than in brackish or seawater. Abrupt salinity change would have apparently long-term negative effects on growth and health conditions. Therefore, mudskippers reared in salinities lower than brackish or seawater should be given gradual acclimation to reduced salinity if the husbandry practice calls for long-term raising in freshwater.

\section{ACKNOWLEDGEMENTS}

This study was supported by the Aquatic Animal Health \& Diseases Department, School of Veterinary Medicine at Shiraz University through a research grant to the first author.

\section{REFERENCES}

Agorreta, A., D. San Mauro, U. Schliewen, J. L. Van Tassell, M. Kovačić, R. Zardoya \& L. Rüber, 2013. Molecular phylogenetics of Gobioidei and phylogenetic placement of European gobies. Molecular Phylogenetics and Evolution, 69, 619-633.

Ajani, F., O. A. Olukunle \& S. A. Agbede, 2007. Hormonal and hematological response of Clarias gariepinus (Burchell 1822) to nitrite toxicity. Journal of Fish International, 2, 48-53.

Akinrotimi, O. A., B. Uedeme-Naa \& E. O. Agokei, 2010. Effects of acclimation on haematological parameters of Tilapia guineensis. Science World Journal, 5, 1-4.

Akinrotimi, O. A., E. O. Agokei \& A. A. Aranyo, 2012. Changes in blood parameters of Tilapia guineensis exposed to different salinity levels. Journal of Environmental Engineering and Technology, 1, 412.

Aligaen, J. C. \& D. D. Mangao, 2011. Climate Change Integrated education: A Model for Lifelong Learning System SEAMEO RECSAM Penang, Malaysia, A report.

Anderson, D. P. \& A. K. Siwicki, 1995. Basic haematology and serology for fish health programs. In: Diseases in Asian Aquaculture II, eds M. Shari, J. R. Arthur \& R. P. Subasinghe, Manila, Philippines: Philippines Fish Health Section, Asian Fisheries Society, p. 185.

APHA, 1985. Standard Methods for the Examination of Water and Waste Waters, $16^{\text {th }}$ edn, American Public Health Association, Washington, USA.

Aragão, C., B. Costas, L. Vargas-Chacoff, I. Ruiz-Jarabo, M. T. Dinis, \& J. M. Mancera, 2010. Changes in plasma amino acid levels in a euryhaline fish exposed to different environmental salinities. Amino Acids, 38, 311-317.

Ayoola, S. O., M. P. Kuton, A. A. Idowu \& A. B. Adelekun, 2011. Acute toxicity of Nile tilapia (Orechromis niloticus) juveniles exposed to aqueous and ethanolic extracts 
Haematological, blood biochemical and immunological responses to gradual acclimation to ....

of Ipomoea aquatic leaf. Nature and Science, 9, 91-99.

Begg, K. \& N. W. Pankhurst, 2004. Endocrine and metabolic responses to stress in a laboratory population of the tropical damselfish Acanthochromis polyacanthus. Journal of Fish Biology, 64, 133-145.

Birrer, S. C., T. B. H. Reusch \& O. Roth, 2012. Salinity change impairs pipefish immune defense. Fish and Shellfish Immunology, 33, 1238-1248.

Blaber, S. J. M., 1997. Fish and Fisheries of Tropical Estuaries, Chapman and Hall, London.

Caruso, G., L., Genovese, G. Maricchiolo \& A. Modica, 2005. Haematological, biochemical and immunological parameters as stress indicators in Dicentrarchus labrax and Sparus aurata farmed in off-shore cages. Aquaculture International, 13, 6773.

Choi, K., W. G. Cope, C. A. Harms \& J. M. Law, 2013. Rapid decreases in salinity, but not increases, lead to immune dysregulation in Nile tilapia (Oreochromis niloticus L). Journal of Fish Diseases, 36, 389399.

Clayton, D. A., 1985. Ecology of mudflats with particular reference to those of the northern Persian Gulf. In: Marine Environment and Pollution: Proceedings of the Conference on the Marine Environment and Pollution, eds R. Halwagy, D. Clayton \& M. Behbehani (eds.), Kuwait University, Kuwait Foundation for the Advancement of Science and Environmental Protection Council, Kuwait City, Kuwait, pp. 83-96.

Colombini, L., R. Berti, A. Ereolini, L. Nocita \& L.Chelazzi, 1995. Environmentals factors influencing the zonation and activity patterns of a population of Periophthalmus sobrinus Eggert in a Kenyan mangrove. Journal of Experimental Marine Biology and Ecology, 190, 135-194.

Davis, A. K., D. L. Maney \& J. C. Maerz, 2008. The use of leukocyte profiles to measure stress in vertebrates: A review for ecologists. Functional Ecology, 22, 760 772 .

Dominguez, M., A. Takeruma \& M. Tsuchiya, 2005. Effects of changes in environmental factors on the non-specific immune response of Nile tilapia, Oreochromis niloticus L, Aquaculture Research, 36, 391397.

Elahee, K. B. \& S. Bhagwant, 2007. Hematological and gill histopathological parameters of three tropical fish species from a polluted lagoon on the west coast of Mauritius. Ecotoxicology and Environmental Safety, 68, 361-371.

Fazio, F., S. Marafioti, F. Arfuso, G. Piccione \& C. Faggio, 2013. Influence of different salinity on haematological and biochemical parameters of the widely cultured mullet, Mugil cephalus. Marine and Freshwater Behaviour and Physiology, 46, 211-218.

Francis, A., F. D. Sikoki \& E. J. Ansa, 2007. Physicochemical parameters of the Andoni rivers systems - Niger Delta, Nigeria. Journal of Fisheries International, 2, 27-31.

Fernandes, M. N. \& A. F. Mazon, 2003. Environmental pollution and fish gill morphology. In: Fish Adaptation, eds A. L. Val \& B. G. Kapoor, Science Publishers, Enfield, pp. 203-231.

Fevolden, S. E., K. H. Roed, , K. T. Fjalestad \& J. Stien, 1999. Post-stress levels of lysozyme and cortisol in adult rainbow trout: heritabilities and genetic correlations. Journal of Fish Biology, 54, 900-910.

Fevolden, S. E., K. H. Røed \& K. Fjalestad, 2003. A combined salt and confinement stress enhances mortality in rainbow trout (Oncorhynchus mykiss) selected for high stress responsiveness. Aquaculture, 216 , 67-76.

Gabriel, U. U., P. E. Anyanwu, A. O. Anyanwu \& A. O. Akinrotimi, 2007. Effect of freshwater challenge on the blood characteristics of Sarotherodon melanotheron. Agricultural Journal, 2, 388-391.

Ghanbarifardi, M. \& M. Malek, 2007. Permanent intertidal fish from the Persian Gulf 
and Gulf of Oman, Iran. Iranian Journal of Animal Biosystematics, 3, 1-14.

Ghanbarifardi, M., S. Ghasemian, M. Aliabadian \& A. Pehpuri, 2014a. Length-weight relationships for three species of mudskippers (Gobiiformes: Gobionellidae) in the coastal areas of the Persian Gulf and Gulf of Oman, Iran. Iranian Journal of Ichthyology, 1, 29-31.

Ghanbarifardi, M., M. Aliabadian, H. R. Esmaeili \& G. Polgar, 2014b. Morphological divergence in the Walton's Mudskipper, Periophthalmus waltoni Koumans, 1941, from the Persian Gulf and Gulf of Oman (Gobioidei: Gobiidae). Zoology in the Middle East, 60, 133-143.

Ghanbarifardi, M., M. Aliabadian \& H. R. Esmaeili, 2014c. Morphometric variation of Periophthalmus waltoni Koumans, 1941 (Teleostei: Gobiidae) in the Persian Gulf and Gulf of Oman. Iranian Journal of Animal Biosystematics, 10, 137-144.

Ghanbarifardi, M., H. R. Esmaeili, Z. Gholami, M. Aliabadian, \& B. Reichenbacher, 2016. Molecular phylogeny of three mudskippers (Gobiidae) from the Persian Gulf and Gulf of Oman (Makran) Sea. Journal of Applied Ichthyology, 32, 416-420.

Girling, P., J. Pupper \& B. Nowal, 2003. Effect of acute salinity and water quality change on juvenile green back flounder, Rhombosolea taprina. Acta Ichthyologia Pistorica, 22, 1-16.

Goldenfarb, P. B., F. P. Bowyer, T. Hall \& E. Brosious, 1971. Reproducibility in the hematology laboratory: The microhematocrit determination. American Journal of Clinical Pathology, 56, 35-39.

Fox, H. E., S. A. White, M. F. Koa \& R. D. Fernald, 1997. Stress and dominance in a social fish. The Journal of Neuroscience, $16,6463-6469$.

Haider, G., 1973. Comparative studies of blood morphology and haemopoiesis of some teleost. observations on cells of the red series, Journal of Zoology, 179, 355383.
Herrera, M., C. Aragão, I. Hachero, I. RuizJarabo, L. Vargas-Chacoff, J. M. Mancera \& L. E.Conceição, 2012. Physiological short-term response to sudden salinity change in the Senegalese sole (Solea senegalensis). Fish Physiology and Biochemistry, 38, 1741-1751.

Hosseini, S. M., S. A. Hosseini \& A. Jafar Nodeh, 2011. Serum biochemical characteristics of Beluga, Huso huso (L.), in response to blood sampling after clove powder solution exposure. Fish Physiology and Biochemistry, 37, 567-572.

Hrubec, T. C., J. L. Robertson \& S. A. Smith, 1997. Effects of temperature on hematologic and serum biochemical profiles of hybrid striped bass (Morone chrysops $x$ Morone saxatilis). The American Journal of Veterinary Research, 58, 126-130.

Jiang, I. F., V. Bharath Kumar, D. N. Lee \& C. F. Weng, 2008. Acute osmotic stress affects tilapia (Oreochromis mossambicus) innate immune responses. Fish \& Shellfish Immunology, 25, 841-846.

Jain, N. C., 1993. Essentials of Veterinary Hematology, Lea and Febiger, Philadelphia, p. 417.

Jian, J. \& Z. Wu, 2003. Effects of traditional Chinese medicine on non-specific immunity and disease resistance of large yellow croaker, Pseudosciaena crocea (Richardson). Aquaculture, 218, 1-9.

King, R. P. \& M. T. Udo, 1997. Vegetation succession-mediated spatial heterogeneity in theenvironmental biology of Periophthalmus barbarous (Gobiidae) in the estuarine swamps of Imo River, Nigeria. International Journal of Surface Mining, Reclamation and Environment, 11, 151154.

Kwapinski, J. B., 1965. Methods of Serological Research. John Wiley and Sons, New York.

Liebert, A. M. \& C. B. Shreck, 2006. Effect of acute stess on osmoregulation, feed intake, IGF-I, and cortisol in yearling steelhead trout (Oncorhynchus mykiss) during sea- 
Haematological, blood biochemical and immunological responses to gradual acclimation to ....

water adaptation. General and Comparative Endocrinology, 148, 195-202.

Chun-yin, L., 2001. Influence of salinity on urea and ammonia metabolism in silver seabream (Spams sarba). Master thesis. The Chinese University of Hong Kong. Hong Kong.

Maceda-Veiga, A., M. Monroy, G. Viscor \& A. De Sostoa, 2010. Changes in nonspecific biomarkers in the Mediterranean barbel (Barbus meridionalis) exposed to sewage effluents in a Mediterranean stream (Catalonia, NE Spain). Aquatic Toxicology, 100, 229-237.

Marc, A. M., C. Quentel, A. Severe, P. Y. Le Bail \& G. Boeuf, 1995. Changes in some endocrinological and non-specific immunological parameters during seawater exposure in the brown trout. Journal of Fish Biology, 46, 1065-1081.

McCormick, S. D., 2001. Endocrine control of osmoregulation in fish. American Zoologist, 282, 290-300.

McCormick, S. D., 2015. Endocrine control of osmoregulation in teleost fish. Integrative and Comparative Biology, 41, 781-794.

Mleczko, R., 2003. Mudskippers: The Periophthalmus species, Part 3. Journal of International Goby Society, 2, 9.

Mommsen, T. P., 1984. Metabolism of the fish gill. In: Fish Physiology, vol XB, eds W. S. Hoar and D. J. Randall, Academic Press, New York, USA. pp. 203-238.

Murdy, E. O., 1989. A taxonomic revision and cladistic analysis of the Oxudercine gobies (Gobiidae: Oxudercinae). Records of the Australian Museum, 11, 1-93.

Mustafayev, N. J. \& A. A. Mekhtiev, 2008. Changes of the serotonergic system activity in fish tissues during an increase of water salinity. Journal of Evolutionary Biochemistry and Physiology, 44, 69-73.

Nordlie, F. G. \& D. C. Haney, 1998. Adaptations in salt marsh teleosts to life in waters of varying salinity. Italian Journal of Zoology, 65, 405-409.
Pulsford, A. L., S. L. Gony, M. Tomlinson, N. Collingwood \& P. J. Glynn, 1994. Effects of acute stress on the immune system of the dab (Limanda limanda). Comparative Biochemistry Physiology, 9, 129-139.

Rahimian, H. \& A. Pehpuri, 2006. Intertidal fishes of Qeshm island, the Persian Gulf. I. Gobiidae (Pisces: Perciformes). Journal of Science, 33, 69-76.

Riche, M., 2007. Analysis of refractometry for determining total plasma protein in hybrid striped bass (Morone chrysops $\times$ M. saxatilis) at various salinities. Aquaculture, 264, 279-284.

Rolland, R. M., M. Gilbertson \& R. E. Peterson, 1997. Chemically induced alterations in functional development and reproduction in fishes, SETAC Press, Pensacola, FL pp. 194.

Ruscoe, I. M., C. C. Shelley \& G. R. Williams. 2004. The combined effects of temperature and salinity on growth and survival of juvenile mud crabs (Scylla serrata). Aquaculture, 238, 239-247.

Salati, A. P., A. Baghbanzadeh, M. Soltani, R. Peyghan \& G. Riazi, 2010. The response of plasma glucose, lactate, protein and hematological parameters to osmotic challenge in common carp (Cyprinus carpio). International Journal of Veterinary Research, 4, 49-52.

Schmitz, M., J. Douxfils, S. N. M. Mandiki, C. Morana, S. Baekelandt \& P. Kestemont, 2016. Chronic hyperosmotic stress interferes with immune homeostasis in striped catfish (Pangasianodon hypophthalmus, S.) and leads to excessive inflammatory response during bacterial infection. Fish \& Shellfish Immunology, 55, 550-558.

Schaperclaus, W., H. Kulow \& K. Schreckenbach, 1991. Hematological and serological technique. In: Fish Disease vol. $1,2^{\text {nd }}$ edn, ed V. S. Kothekar, Oxonian press New Delhi: Gulabprimlani, pp. 71-108.

Skouras, A., 2002. The use of piscine innate immune responses as indicators for environmental pollution in marine ecosystems. $\mathrm{PhD}$ Thesis. 
Steinhagen, D., P. Kruse, \& W. Körting, 1990. Some haematological observations on carp Cyprinus carpio L. experimentally infected with Trypanoplasma borelli Laveran and Mesnil. 1901 (Protozoa: Kitenoplastida). Journal of Fish Diseases, 14, 157-162.

Svobodová, Z., M. Flajshans, H. Modrá, M. Svoboda \& V. Vajcová, 2001. Leukocytes profiles of diploid and triploid tench, Tinca tinca L. Aquaculture, 198, 159-168.

Thompson, I., A. White, T. C. Fletcher, D. F. Houlihan \& C .J. Secombes, 1993. The effect of stress on the immune response of Atlantic salmon (Salmo salar L.) fed diets containing different amounts of vitamin $\mathrm{C}$. Aquaculture, 114, 1-18.

Trinder, P., 1969. Determination of glucose in blood using glucose oxidase with an alternative oxygen acceptor. Annals of Clinical Biochemistry, 6, 24-27.

Tytler, P. \& T. Vaughan, 1983. Thermal ecology of the mudskippers Periophthalmus koelreuteri (Pallas) and Boleophthalmus boddaerti (Pallas) of Kuwait Bay. Journal of Fish Biology, 23, 327-337.

Sasekumar, A., 1994. Meiofauna of a mangrove shore on the west coast of peninsular Malaysia. Raffles Bulletin of Zoology, 42, 901-915.

Vazzana, M., M. Cammarata, E. L. Cooper \& N. Parrinello, 2002. Confinement stress in sea bass (Dicentrarchus labrax) depresses peritoneal leukocyte cytotoxicity. Aquaculture, 210, 231-243.

Woo, N. Y. S. \& J. C. Murat, 1981. Studies on the biology of red sea bream Chrysophyrys major III. Metabolic response to starvation in different salinities. Marine Biology, 6 , 255-260.

Wootton, R. J., 1990. Ecology of Teleost Fishes. Chapman and Hall, London, p. 398.
Wang, Y. F. \& X. H. Zhu, 2002. A review on impact of salinity on patterns of fish ecophysiology. Studia Marina Sinica, 44, 151-158.

Woo, N. Y. S. \& R. S. S. Wu, 1982. Metabolic and osmoregulatory changes in response to reduced salinities in the red grouper, Epinephelus akaara (Temminck and Schlegel), and the black sea bream Mylio macrocephalus (Basilewsky). Journal of Experimental Marine Biology and Ecology, 65, 139-161.

Yada, T., T. Azuma \& Y. Takaji, 2001. Stimulation of non-specific immune functions in seawater-acclimated rainbow trout $\mathrm{On}$ corhynchus mykiss, with reference to the role of growth hormone. Comparative Biochemistry and Physiology Part B, 129, 695-701.

Zhou X., C. Niu, R. Sun \& Q. Li, 2002. The effect of vitamin $\mathrm{C}$ on the non-specific immune response of the juvenile softshelled turtle, Trionyx sinensis. Comparative Biochemistry and Physiology, 131A, 917-922.

Paper received 30.01.2017; accepted for publication 07.04.2017

\section{Correspondence:}

Siyavash Soltanian, Aquatic Animal Health \& Diseases Dept, School of Veterinary Medicine,

Shiraz University, 71441-69155 Shiraz, Iran, tel: +98 $7136138906,+989173364632$, fax: +987132286950 , e-mail: siyavashsoltanian@yahoo.com 